\title{
Linguagens
}

\section{ESTRATÉGIAS DE COMPREENSÃO LEITORA NA UNIVERSIDADE}

\author{
Marcela Tavares de Mello (FASAP)
}

\begin{abstract}
RESUMO: É notória e inquestionável a importância da compreensão textual no meio acadêmico, tendo em vista que os conhecimentos transmitidos na universidade são compartilhados, principalmente, através dos textos. Por isso, torna-se basilar para o futuro desenvolvimento cognitivo e, consequentemente, profissional dos graduandos que a compreensão textual se efetive de maneira eficaz. Foi, a partir desse contexto, que surgiu a motivação para realizar este trabalho que teve como objetivo reunir contribuições de teóricos que se dedicaram a elaborar estratégias de leitura para auxiliar os graduandos no processo de compreensão dos textos que circulam na academia. Para elaboração do mesmo, foi necessário lançar mão de uma pesquisa bibliográfica com intuito de aproximar teoria científica e prática pedagógica. No decorrer do estudo, ficou evidente a importância da leitura na vida dos acadêmicos bem como o papel fundamental dos professores no processo de intervenção através de estratégias que auxiliem os discentes a compreender e dialogar com os textos presentes na academia.
\end{abstract}

PALAVRAS-CHAVE: Leitura. Estratégias de Leitura. Universidade. Letramento Acadêmico.

\begin{abstract}
There is no doubt the importance of textual comprehension in academic community, considering that the knowledge imparted in the University are shared mainly through the texts, this way reading is an essential element to the educational methodology. Therefore, it becomes very important to the future cognitive development and consequently professional textual comprehension of graduating happens in an effective way. From this context that emerged from our motivation to perform this work that aimed to bring theoretical contributions that dedicated themselves to develop reading strategies to assist the student in the process of comprehension of texts spreading in the Academy. For the preparation of same, was necessary to use a bibliographical research in order to bring scientific theory and pedagogical practice. In the course of the study it became evident the importance of reading in the lives of academics as well as the key role of teachers in the process of intervention through strategies which help the students to understand and engage with the present texts in the Academy.
\end{abstract}

KEYWORDS: Reading. Reading strategies. University.

\section{INTRODUÇÃO}

Nos últimos anos, houve um aumento considerável do acesso ao ensino superior no Brasil, fruto do crescente número de faculdades e das diversas formas de ingresso nas mesmas. Obviamente, a inserção de um número maior de estudantes na graduação trouxe um avanço significativo para a sociedade, contudo, o ingresso nas instituições não garantiu o bom desempenho dos graduandos, como apontam várias pesquisas (ALCARÁ, 2012; JUNIOR, 2011; PULLIN, 2011; SÉLIS, 2008) que retratam as dificuldades que esses alunos encontram ao ingressar nas universidades. 


\section{Singuagens}

Uma das tensões apontadas nessas pesquisas sobre a inserção dos estudantes no ensino superior está associada à dificuldade que eles encontram em lidar com a linguagem dos textos presentes na academia, ou seja, na deficiência de produzir e compreender textos que circulam no ambiente acadêmico, o que acaba comprometendo o desenvolvimento dos mesmos.

Além da deficiência dos alunos, é percebida também a preocupação de parte dos professores universitários em lidar com essa situação. Por um lado, sabe-se que essa deficiência é oriunda de um ensino médio completamente comprometido em nosso país, por outro lado, o professor é consciente de que a deficiência relacionada ao uso da linguagem dificulta muito o processo de ensino aprendizagem desses discentes e, portanto, busca subsídios para tentar sanar as dificuldades dos mesmos.

Além disso, da carência associada à linguagem, ao ingressarem na universidade, é exigido que esses alunos produzam e compreendam gêneros textuais específicos da esfera acadêmica, com os quais, muitas vezes, não tiveram nenhum tipo de contato, o que dificulta ainda mais o processo de ensino aprendizagem.

É sabido que, para que o ensino se efetive de maneira eficaz, os professores necessitam sanar essa deficiência trazida pelos alunos, letrando-os academicamente. Parte desses professores não faz nenhuma interferência que objetive auxiliar esses alunos, e a outra parte que se compromete com o desenvolvimento dos mesmos, quando buscam auxílio através de subsídios teóricos, encontra uma escassez imensa de metodologias voltadas para lidar com a linguagem na universidade.

Diante do exposto, no presente estudo, procuramos reunir contribuições, ainda que sem esgotá-las, de teóricos que se dedicaram a pesquisar sobre o letramento acadêmico, elaborando estratégias para o uso da linguagem na universidade. Com isso, pretendemos também, aproximar teoria científica e prática pedagógica. Sabemos que a produção e a compreensão textual são processos indissociáveis, porém nesse trabalho daremos ênfase apenas às habilidades e estratégias relacionadas à leitura.

Organizamos o texto da seguinte forma. Na primeira parte, apresentamos sucintamente os pontos de vista teóricos sobre a importância da leitura e da formação de sujeitos da leitura. Posteriormente, difundimos algumas estratégias que podem ser utilizadas pelos docentes da 


\section{S Linguagens}

graduação a fim de ajudar os alunos a criarem mecanismos que os auxiliem no processo de compreensão textual. Por fim, realizamos uma breve consideração sobre o estudo realizado.

\section{A LEITURA NA UNIVERSIDADE}

É inquestionável a importância da leitura para a inserção social dos indivíduos nos mais variados contextos pelos quais circulam. Além de proporcionar o acesso à informação, a leitura propicia o desenvolvimento de várias habilidades como a criatividade e o espírito crítico dos indivíduos.

Assim como nos variados contextos, a compreensão textual é de extrema importância no meio acadêmico, tendo em vista que os conhecimentos transmitidos na universidade são compartilhados, principalmente, através dos textos, sendo a leitura um elemento essencial à metodologia educacional. Sendo assim, torna-se basilar para o futuro desenvolvimento cognitivo e, consequentemente, profissional dos graduandos que a compreensão textual se efetive de maneira eficaz.

$\mathrm{O}$ ato da leitura não consiste apenas em decodificar as palavras, ou seja, perceber apenas o que está escrito. $\mathrm{O}$ ato de ler significa integrar o que os textos trazem com o conhecimento de mundo do leitor, tornando-se necessário discutir e dialogar com seu autor, como lembrou Freire (2001).

Esse conceito vai ao encontro das palavras de Marcuschi (2008, p. 228), quando enfatiza que "ler é um ato de produção e apropriação de sentido que nunca é definitivo e completo [...] não é um ato de simples extração de conteúdos ou identificação de sentidos". Para o autor, a compreensão está associada a aspectos cognitivos internalizados ao longo da nossa vida social, no coletivo, e não aos aspectos individuais e únicos. Face a isto, a leitura deve ser promovida "como uma ação solidária e coletiva no seio da sociedade" (ibidem, p. 232).

A postura assumida pelo leitor durante a leitura interfere diretamente na compreensão do texto, podendo ele ser um sujeito da leitura ou um objeto da leitura.

Os fatores que distinguem esses dois tipos de leitor foram apontados por Luckesi (2005) quando evidenciou que o leitor-objeto não se compromete com a construção de novos 


\section{S Linguagens}

conhecimentos seu objetivo é apenas armazenar as informações presentes nos textos e reproduzi-las quando necessário. Em outras palavras, não critica, não investiga nem dialoga com o texto. Ao contrário, o leitor-sujeito é aquele que, durante a leitura, adquire uma postura crítica e comunicativa com o texto, sendo capaz de produzir variados sentidos ao texto e, até mesmo, tornar-se um leitor-autor ao expressar novas interpretações da realidade.

A universidade precisa de leitores que desenvolvam uma postura ativa durante a leitura, ou seja, de leitor-sujeito. Para Luckesi (2005), três pontos precisam ser enfatizados a fim de conscientizar o leitor de seu papel e torná-los sujeitos de leitura: ler não é apenas memorizar; ler é avaliar e fazer referência com a realidade; e ler é questionar e dialogar com o autor do texto.

Para a formação de sujeitos ativos, além dos aspectos sociais da compreensão, citados anteriormente por Marcuschi, outro fator importante que deve ser levado em conta durante o processo da leitura é o reconhecimento das características do texto em estudo: o gênero textual, finalidade, estrutura, interlocutores, linguagem. Essa percepção auxilia o leitor a compreender o contexto de produção do texto, facilitando a interação com o mesmo.

No entanto, lamentavelmente, várias pesquisas apontam (MELLO, 2014; RESENDE, 2010; SANTOS, 2005) que na educação básica a realidade do trabalho realizado pelos professores é outra. Os exercícios de compreensão ainda contemplam apenas a decodificação dos textos, deixando de lado a interpelação crítica, ou seja, o questionamento do contexto de produção de determinado texto: objetivo, interlocutor, visão do mundo e da ciência que veicula, etc. Os professores não incentivam o diálogo entre o leitor e o autor do texto.

Além dos resultados dessas pesquisas, outro dado alarmante é o resultado do Programa Internacional de Avaliação de Estudantes $(\mathrm{PISA})^{1}$. Nesse exame, que participam 65 países, o

\footnotetext{
${ }^{1}$ O Programa Internacional de Avaliação de Estudantes é uma iniciativa internacional de avaliação comparada, aplicada a estudantes na faixa dos 15 anos, desenvolvido e coordenado pela Organização para Cooperação e Desenvolvimento Econômico (OCDE), no Brasil, coordenado pelo INEP. O objetivo do Pisa é produzir indicadores que contribuam para a discussão da qualidade da educação nos países participantes, de modo a subsidiar políticas de melhoria do ensino básico. A avaliação procura verificar até que ponto as escolas de cada país participante estão preparando seus jovens para exercer o papel de cidadãos na sociedade contemporânea.
} 


\section{Linguagens}

Brasil ficou na $55^{\mathrm{a}}$ posição no ranking de leitura, somando apenas 410 pontos, dois a menos do resultado obtido na última avaliação que ocorreu em 2009.

Além dessas questões oriundas da educação básica que comprometem o processo de compreensão textual dos graduandos, outro aspecto que merece destaque: o público alvo dos textos científicos são especialistas do assunto que trazem consigo conhecimentos prévios sobre determinadas questões que auxiliam na compreensão dos mesmos. Esses conhecimentos geralmente ainda não foram desenvolvidos pelos graduandos, uma vez que a maior parte dos alunos ao menos havia tido contato anteriormente com textos científicos.

Severino (2007, p. 49) acrescenta que

[...] habituados à abordagem de textos literários, os estudantes, ao se defrontarem com textos científicos ou filosóficos, encontram dificuldade logo julgadas insuperáveis e que reforçam uma atitude de desânimo e de desencanto, geralmente acompanhada de um juízo de valor depreciativo em relação ao pensamento teórico.

Dentre as dificuldades relacionadas à leitura por parte dos graduandos, Boruchovitch e Santos (2001) apontam: a escassez de vocabulário, a falta de motivação, o embaraço durante a leitura oral, as deficiências no processo de decodificação, a incapacidade de assimilação das informações e da memória. Além disso, os autores destacam a ausência de estratégias que auxiliem a compreensão.

Diante do exposto acima, torna-se notório entender o porquê das inúmeras dificuldades encontradas pelos alunos, quando ingressam na graduação, em compreender os textos que circulam na academia.

Para que os discentes possam sanar essas deficiências e obter sucesso na formação, faz-se necessário que os professores universitários os motivem e auxiliem apresentando estratégias específicas que possibilitem direcionar a compreensão desses textos e colaborem para a formação de sujeitos críticos e reflexivos com intuito de que os graduandos adotem uma postura de "leitor-acadêmico" (DAUSTER, 2003).

\section{ESTRATÉGIAS DE LEITURA NA GRADUAÇÃO}




\section{S Linguagens}

Denominam-se estratégias os métodos utilizados para alcançar o objetivo proposto, no caso em estudo, a compreensão textual. Podem ser elucidadas também, como procedimentos processuais que possibilitam a aquisição, armazenamento e utilização eficaz das informações (POZO, 1996). Em síntese, as estratégias são elementos que facilitam os processos de compreensão e apreensão dos textos. Para que os graduandos possam utilizar tais estratégias, faz-se necessário que eles as compreendam.

Quanto maior a frequência da sua utilização, mais facilidade o leitor tem para integrálas como processo natural no momento da leitura. Outro fator importante relaciona-se à consciência necessária em saber quando e como utilizá-las.

O pesquisador Main (1985, apud MONEREO, 1990, p. 12) destaca que as estratégias de aprendizagem mais eficientes são àquelas que surgem através da reflexão crítica do aluno sobre suas próprias práticas de aprendizagem.

Monereo (1990, p. 12) aponta ainda alguns métodos que os professores podem lançar mão a fim de auxiliar os discentes na elaboração de estratégias de aprendizagem:

1. Introduzir atividade que promovam a reflexão dos alunos sobre seus mecanismos de aprendizagem.

2. Oferecer a oportunidade de refletir e debater sobre os processos e táticas de aprendizagem de outros.

3. Facilitar a aplicação seletiva das estratégias de aprendizagem identificadas como eficazes, com práticas em sala de aula.

4. Refletir sobre os processos de aprendizagem implicados em tarefas da vida diária.

5. Colaborar na implantação de novas habilidades e estratégias ao longo de todas as áreas curriculares (traduzido pela autora).

Kopke (1997) menciona dois tipos de estratégias que podem ser utilizadas para trabalhar a leitura: cognitivas e metacognitivas. As estratégias cognitivas se relacionam com a maneira de pensar e se comportar durante o processo. Os modos influenciam a apreensão do conteúdo em estudo. São métodos que os discentes utilizam a fim de apreender os conteúdos propostos.

Já as estratégias metacognitivas referem-se ao controle, à consciência e ao conhecimento do leitor em relação à utilização da cognição, em outras palavras, os métodos por ele utilizados para compreender o texto. Três habilidades são essenciais à utilização das estratégias metacognitivas, a saber, planejar, monitorar e regular o processo de compreensão. 


\section{S Linguagens}

A habilidade de planejar consiste em fixar metas de estudo; o monitoramento refere-se à capacidade do leitor em avaliar sua compreensão durante a leitura; e a ação de regular associa-se ao monitoramento, quando o leitor é capaz de detectar as deficiências e modificar seu comportamento no decorrer do processo da compreensão textual.

Muitas pesquisas (SÉLIS, 2008; JOLY, 2007; ALCARÀ, 2012; KOPKE, 1997) comprovaram que o êxito dos graduandos, relacionado à compreensão textual, está diretamente associado à motivação e à utilização de estratégias aplicadas. Tendo em vista os resultados obtidos nas pesquisas e o objetivo deste trabalho, divulgaremos algumas estratégias apresentadas por Jacobowitz (1990), Ogle (1986) e Severino (2007).

\subsection{Estratégia proposta por Jacobowitz}

$\mathrm{Na}$ estratégia denominada Author's Intended Message (AIM), proposta pela pesquisadora Jacobowitz (1990), a autora focaliza na forma com que é realizado o trabalho de compreensão quando o objetivo é encontrar a ideia principal de um texto. Segundo Jacobowitz (1990) o trabalho realizado nos segmentos que precedem a universidade acontece de forma ineficaz, pois os professores ensinam para os alunos que a ideia central de um texto é imanente a ele e que pode ser encontrada na superfície do texto, o que leva o aluno a ter uma postura passiva perante o texto, ou seja, apenas um receptor de conhecimentos.

A autora destaca ainda que as pesquisas realizadas recentemente mostram que, para compreender a ideia central de um texto, o leitor deve construir um sentido para o mesmo, efeito de um processo ativo do leitor onde o leitor é capaz de criar ideias e não apenas descobri-las. Esses resultados evidenciam a ineficácia relacionada ao ensino da compreensão textual.

O leitor considerado hábil, quando é solicitado que encontre a ideia principal do texto, é capaz de

a) interagir com texto, no sentido de relacionar seu conhecimento prévio com o conhecimento acumulado durante a leitura;

b) fazer uso de palavras-chave ou de frases para encontrar a intenção do autor;

c) resumir a matéria lida em uma única ideia e 
d) demonstrar as estratégias que costumam usar como plano para chegar à compreensão do texto. (KOPKE, 1990, p. 62).

Com base nessas diferentes formas de trabalhar a compreensão textual, diferenças essas que formam leitores ativos ou leitores passivos, que foi elaborada a estratégia AIM (mensagem pretendida pelo autor) tendo como fim a formação de leitores ativos capazes de realizar a leitura de maneira significativa. Para isso, Jacobowitz (1990) delineou alguns objetivos específicos relacionados às habilidades que devem ser adquiridas pelos leitores:

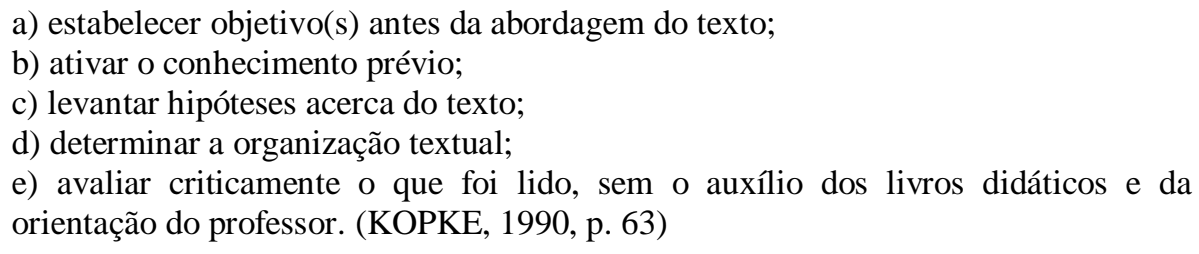

Essas habilidades citadas anteriormente pela estratégia AIM são realizadas em três momentos: antes, durante e depois da leitura. Destaca-se ainda que é função do professor instruí-las.

$\mathrm{Na}$ pré-leitura, a autora sugere que os professores realizem questões direcionadas ao texto que será lido: a) o tema é polêmico? b) que conhecimento o aluno tem desse assunto? c) o assunto é polêmico para ele? d) ele tem alguma opinião formada a seu respeito? e) o que ele espera descobrir? f) que perguntas serão respondidas após a leitura? g) quem é o autor? h) que texto(s) de sua autoria já foi/foram lido(s) pelo aluno? i) há conhecimento de informações acerca desse autor que possam servir de auxílio à compreensão da mensagem?

No momento da leitura, são realizadas as seguintes questões: a) o autor apresentou uma introdução em que expõe os pontos mais importantes do texto? b) é possível se fazer uma paráfrase da introdução? c) enquanto lê, o aluno concentra sua atenção em palavras ou frases que denotam um modelo particular de estrutura como, por exemplo, comparação/contraste, causa/efeito? d) caso isso ocorra, ele é capaz de construir a ideia principal que reflete essa estrutura? e) o autor forneceu algumas conclusões ou um resumo que permitam dizer o que ele pretende com a mensagem? f) foram feitas perguntas apropriadas antes de o aluno começar a leitura? g) há condição de ele responder a qualquer uma? h) que outras perguntas podem ser feitas ainda? 


\section{S Linguagens}

Por fim, depois de lido o texto, são levantadas questões como: a) qual foi, segundo a opinião do aluno, a intenção do autor ao escrever o texto? b) essa intenção corresponde à expectativa do aluno antes de fazer a leitura? c) se não, quais foram as perguntas respondidas pelo autor? d) o aluno concorda com a opinião ou conclusão do autor? e) é capaz de fazer uma paráfrase ou resumo da matéria? f) há itens e subitens que o auxiliem nessa tarefa?

Essa estratégia, como foi enfatizada anteriormente, objetiva auxiliar o professor a ajudar ao aluno a encontrar a ideia principal do texto. Se mesmo depois de realizadas as questões propostas, o aluno não encontrar a mensagem pretendida pelo autor, ele deve: reler o texto, lê-lo superficialmente, retomar as questões propostas, levantar outras questões ou discutir com um colega (ibidem, p. 64).

\subsection{Estratégia proposta por Ogle}

Outra estratégia elaborada para compreensão textual de textos teóricos é a estratégia denominada K-W-L, criada por Ogle (1986). O objetivo dessa estratégia e fazer com que a compreensão aconteça através do conhecimento prévio que o leitor tem sobre determinado assunto, uma vez que esse conhecimento interfere na maneira de interpretar e aprender com a leitura.

Assim como a estratégia descrita anteriormente, a K-W-1 sugere ações antes, durante e depois da realização da leitura.

$\mathrm{Na}$ fase anterior ao momento da leitura, denominada de fase $\mathrm{K}$ (What I know), o professor realiza questões sobre o assunto a ser abordado a fim de verificar o conhecimento que o aluno tem sobre o mesmo. Segundo Kopcke (1990), essas questões estimulam os alunos a pensar provocando uma tempestade cerebral. As respostas são inseridas num quadro na coluna da fase $\mathrm{K}$

Posteriormente, na fase W (What I wanttoKnow) os alunos assinalam as questões que pretendem saber sobre o assunto, e, durante ou após realizar a leitura escrevem no quadro as questões que foram respondidas pelo texto. Faz-se necessário que o professor tenha um conhecimento intrínseco sobre o assunto a ser trabalho para que possa auxiliar os alunos na construção de suas questões. 


\section{Singuagens}

Por fim, a fase L (What I Learned) é realizada posteriormente ao momento da leitura e tem por objetivo fazer com que os alunos escrevam sobre os conhecimentos adquiridos através da leitura do texto; além disso, devem ser inseridas as respostas das questões realizadas na etapa anterior. $\mathrm{O}$ professor deve atentar aos alunos a verificar se as questões realizadas na fase $\mathrm{W}$ forma respondidas pelo texto. Se isso não tiver acontecido, o professor faz sugestões de novas leituras com o objetivo de responder às questões pretendidas pelos alunos.

\subsection{Estratégia proposta por Severino}

Severino (2007) também faz parte do grupo de pesquisadores que se dedicaram a elaborar estratégias que auxiliam os graduandos na inserção no mundo acadêmico.

Entretanto, em vez de estratégias, ele denominou de diretrizes os procedimentos para a realização de uma leitura eficaz e ativa, propostos por ele. Essas diretrizes, segundo Severino, objetivam:

1. Favorecer a compreensão global do significado do texto;

2. Treinar para a compreensão e interpretação crítica dos textos;

3. Auxiliar no desenvolvimento do raciocínio lógico;

4. Fornecer instrumentos para o trabalho intelectual desenvolvido nos seminários, no estudo dirigido, no estudo pessoal e em grupos, na confecção de resumos, resenhas, relatórios, etc. (ibidem, p. 63).

Esses procedimentos foram divididos em seis momentos: delimitação da unidade de leitura, análise textual, análise temática, análise interpretativa, problematização e crítica. Os procedimentos serão descritos a seguir.

No primeiro passo, denominado "delimitação da unidade de leitura", o autor propõe que o estudo seja realizado por etapas, ou seja, que se delimite a unidade que será estudada. Essa delimitação auxilia o leitor a posteriormente fazer uma síntese do que foi estudado durante as etapas. Outro aspecto destacado nessa diretriz se relaciona com o intervalo de tempo dado entre o estudo das etapas, para o autor o estudo da unidade deve ser realizado de maneira contínua. 


\section{S Linguagens}

Posteriormente, na diretriz "a análise textual”, é realizada uma preparação para a compreensão do texto. Faz-se uma leitura superficial a fim de alcançar uma visão conjunta da unidade. Nessa etapa, o leitor deve: buscar dados relacionados ao autor; conceitos básicos do texto; reportar fatos históricos; organizar um esquema da estrutura do texto.

$\mathrm{Na}$ fase "análise temática",o leitor começa a dialogar com o autor, ainda que sem questioná-lo, com intuito de obter algumas respostas sobre o conteúdo. Ele faz questões como: “Qual é o assunto do texto?”; “Qual é a problematização que o autor traz sobre aquele assunto?"; "Como o autor responde ou que ideia defende sobre o problema trazido por ele (a tese do autor)?"; "Como o autor demonstra, comprova sua tese?"; "Quais são os argumentos por ele utilizados?". Com as respostas a essas questões, é possível elaborar um resumo ou uma síntese do texto em estudo.

Em seguida, na diretriz intitulada "a análise interpretativa", o leitor faz sua própria interpretação a partir das ideias expostas pelo autor. Esse é o momento em que a leitura ultrapassa a simples decodificação do texto, e o leitor se posiciona, baseado na sua vivência e nos conhecimentos prévios adquiridos, sobre o tema exposto, em outras palavras, é o momento da interação entre o leitor e o autor. A análise interpretativa é realizada em quatro momentos.

Primeiramente, o leitor relaciona as ideias do autor com a literatura existente sobre o tema e com o contexto de vida e da obra do autor, essa relação é denominada de lógicoestático. No segundo momento, é realizada a relação designada lógico-dinâmica em que o leitor conecta as ideias do autor com as ideias de teóricos que corroboram com as suas concepções.

Posteriormente, o leitor pesquisa autores que tiveram as mesmas concepções sobre o assunto em discussão, entretanto abordaram o tema de maneira distinta.

Por fim, é realizada uma interpretação crítica do texto levando em consideração dois critérios: primeiro, a coerência interna do texto; segundo, a originalidade e a relevância e contribuições trazidas pelo autor.

Para a realização dessa etapa, é preciso que o leitor tenha conhecimento prévio das questões tratadas no texto, uma vez que o objetivo principal "é o amadurecimento da reflexão pessoal para o tratamento autônomo dessas questões" (ibidem, p. 61). 


\section{S Linguagens}

A quarta diretriz para a compreensão é a fase da "problematização", em que,fazendo uma retomada no texto, o leitor levanta questões (implícitas ou explícitas no texto) e problemas para discutir com o grupo. Segundo Severino, essas discussões são fundamentais à atividade científica e filosófica.

Por fim, a diretriz "síntese pessoal" é produzida a partir das reflexões realizadas nas etapas anteriores. Nesta fase, o leitor reelabora a mensagem passada pelo autor com base no texto e em sua reflexão pessoal.

\section{ALGUMAS (BREVES) CONSIDERAÇÕES}

No decorrer do estudo ficou evidente a importância da leitura na vida dos acadêmicos bem como o papel fundamental dos professores no processo de intervenção através de estratégias que auxiliem os discentes a compreender e dialogar de forma crítica e reflexiva com os textos presentes na academia.

Nas estratégias descritas, é possível verificar que todas as propostas visam desenvolver uma leitura ativa, ou seja, fazer com que os alunos se tornem sujeitos da leitura, corroborando com a interação entre o leitor e o autor. Os teóricos demonstram também a possibilidade e a importância de orientar os graduandos a controlar, avaliar e refletir sobre o processo de aprendizagem durante a leitura.

Apontamos que não foi identificado, em nossas pesquisas, nenhum estudo que tenha se dedicado a aplicar essas estratégias com objetivo de verificar sua efetividade, por isso, não podemos afirmar sobre a eficácia das mesmas. No entanto, em nossas práticas enquanto docentes universitários, são perceptíveis as dificuldades encontradas pelos alunos em compreender e produzir os textos que circulam na academia, seja pela falta do hábito da leitura ou pela falta de contato com textos acadêmicos, ademais percebe-se que essas deficiências afetam de maneira significativa a aprendizagem. Sendo assim, acreditamos na urgência de procurar meios para auxiliar os graduandos a compreender e dialogar com os textos presentes na esfera acadêmica a fim de que eles se sintam, de fato, inseridos no contexto acadêmico. 


\section{Singuagens}

Enfim, para que aconteça a junção da formação intelectual e o trabalho, além do incentivo a pesquisa como elementos constituintes do processo ensino/aprendizagem desses alunos, conforme é proposto pelo Plano Nacional de Educação (PNE), é preciso proporcionar habilidades de compreensão e produção textual em sua dimensão social, a fim de que eles possam interagir de maneira eficaz nos mais variados contextos e se tornem hábeis a produzir novos conhecimentos.

Ressaltamos que este trabalho não teve a pretensão de esgotar o assunto, mas sim reunir contribuições de teóricos que abordam o tema em estudo e aproximar teoria científica e prática pedagógica.

\section{REFERÊNCIAS}

ALCARÁ, A. R. Compreensão de leitura, estratégias de aprendizagem e motivação em universitários: estudos de validade de medidas. Universidade São Francisco. Itatiba, 2012.

BORUCHOVITCH, E.; SANTOS, A. A. A. Escala de Avaliação de Estratégias de Aprendizagem. Bragança Paulista, SP: EDUSF, 2001.

BRASIL. Instituto Nacional de Estudos e Pesquisas Educacionais Anísio Teixeira - INEP. PISA. Disponível em: http://portal.inep.gov.br/pisa-programa-internacional-de-avaliacao-dealunos. Acesso em: 20 jan. 2015.

DAUSTER, T. A invenção do leitor acadêmico: quando a leitura é um estudo. Leitura: Teoria e Prática, Campinas, n. 41, p. 73-83, 2003.

FREIRE, P. A importância do ato de ler. 41 ed. São Paulo: Cortez, 2001.

JACOBOWITZ, T. AIM: A metacognitive strategy for constructing the main idea of text. Journal of Reading, p. 620-624, 1990.

JOLY, M. C. Escala de estratégias metacognitivas de leitura para universitários brasileiros: estudo de validade divergente. Univ. Psychol Bogotá, v.6, p. 507-521. 2007.

JUNIOR, W. E. F. Estratégias de leitura na educação química e na formação docente: necessidades e contribuições de um planejamento crítico. Universidade Estadual Paulista. Araraquara, 2011. 


\section{S Linguagens}

KOPKE, H. F. Estratégias para Desenvolver a Metacognição e a Compreensão de Textos Teóricos na Universidade. Psicologia Escolar e Educacional, 1(2-3), 59-67. 1997.

LUCKESI, C. C. et al. Fazer universidade: uma proposta pedagógica. 14.ed. São Paulo: Cortez, 2005.

MARCUSCHI, L. A. Produção textual, análise de gêneros e compreensão. São Paulo: Cortez, 2008.

MELLO, M. T. Gêneros textuais: teoria e prática numa escola municipal de Pirapetinga. Universidade Católica de Petrópolis. Petrópolis, 2014.

MONEREO, C. Las estratégias de aprendizajeenlaeducacíon formal: enseñar a pensar y sobre el pensar. Infancia y aprendizaje, v. 50, p. 3-25. 1990.

OGLE, D. M. K-L-W: A teaching model that develops active reading of expository text. The Reading Teacher, 39: 564-70, 1986.

PAVÃO, A. A dimensão formadora da universidade na construção do habitua da leitura e da escrita. 27 Reunião da Anped, 2004.

POZO, J. I. Estratégias de aprendizagem. Em: C. Coll, J. Palácios \& A. Marchesi (Orgs.), Desenvolvimento psicológico e educação: psicologia da educação (p. 176-197). Tradução de Angélica Mello Alves. Porto Alegre: Artes Médicas. 1996.

PULLIN, E. M. M. Estratégias de leitura usadas por alunos de graduação e mestrado de educação. Diálogo Educacional, Curitiba, v.11, n.34, p. 971-996, set./dez. 2011.

RESENDE, V. B. Letramento escolar: eventos e apropriações de gêneros textuais por adolescentes; Universidade Federal de Minas Gerais. Belo Horizonte, 2010.

SANTOS, A. O. M. Um gênero é pouco, dois é bom, três nunca é demais... reflexões sobre o uso de textos e as estratégias de leitura na escola. Universidade Federal da Bahia. Salvador. 2005.

SÉLIS, P. S. Compreensão em leitura e estratégias de aprendizagem em universitários. Universidade do Oeste Paulista. Presidente Prudente, 2008.

SEVERINO, A. J. Metodologia do trabalho científico. 23. ed. rev. e atual. São Paulo: Cortez, 2007. 